\title{
IMPACTO DA EDUCAÇÃO SUPERIOR PARA A MOBILIDADE SOCIAL
}

Tiago Alexandre, José Renato da Silva Oliveira, Alexandre Godinho Bertoncello

Universidade do Oeste Paulista - UNOESTE, Curso de Administração, Presidente Prudente, SP. E-mail: bertoncello@unoeste.br

\section{RESUMO}

Na ultima década tivemos um aumento expressivo de pessoas cursando o nível superior no Brasil. A literatura internacional faz uma relação direta entre nível de escolaridade e renda per capita dos países, porém não há trabalhos no contexto do Oeste Paulista. O objetivo deste trabalho foi quantificar se temos os mesmos padrões internacionais da mobilidade social, medindo a renda, os níveis de empreendedorismo e, a satisfação social. Para tal foram pesquisados egressos dos últimos 7 anos do curso de Administração de Empresas de uma universidade no Oeste Paulista, aplicando questionários elaborados segundo a escala Likert e, estudando dados secundários oficiais do IBGE e RAIS. Observou-se que as melhorias socioeconômicas dos ex-alunos estudados são superiores ao relatado na literatura internacional e a média nacional. Ao mesmo tempo foi detectado que o nível de empreendedorismo local é inferior ao nível nacional e o gap entre gêneros dos egressos também esta acima da média nacional.

Palavras - chave: Empreendedorismo; Egressos; Escala Likert; Educação.

\section{IMPACT OF HIGHER EDUCATION FOR SOCIAL MOBILITY}

\begin{abstract}
In the last decade, we have had an expressive increase of people attending higher education in Brazil. The international literature makes a direct relation between level of schooling and income per capita of countries, however there are no studies in the context of the region known as Oeste Paulista. The objective of this study was to quantify if we have the same international standards of social mobility, measuring income, levels of entrepreneurship and social satisfaction. For this research, we have studied graduates of the last 7 years of the Business Administration course of a university located in the countryside of São Paulo, through questionnaires with the Likert scale standard and studying official secondary data from IBGE and RAIS. It was observed that the socioeconomic improvements of the alumni studied are higher than those reported in the international literature and the national average. At the same time, it was detected that the level of local entrepreneurship is lower than the national level and the gap between the genders of former students is also higher than National average.
\end{abstract}

Keywords: Entrepreneurship; Former Students; Likert scale; Education.

\section{INTRODUÇÃO}

As mudanças sociais neste período apontam para dois grandes desafios para os egressos de universidades; a disputa cada vez mais acirrada entre os candidatos no mercado de trabalho e, o dilema de ter uma postura empreendedora e iniciar uma nova atividade econômica, em outras palavras se tornar empreendedor.

Há um consenso que o nível escolar está relacionado com desenvolvimento sócio econômico. Em linhas gerais, quando maior for o nível escolar maior será o desenvolvimento da região, o Banco Mundial, por meio do artigo publicado por Tan et al (2011) relata que o aumento de capacidade de aprendizagem nacional em matemática significa em média um aumento de $2 \%$ no PIB do país. Esse mesmo relatório indica ainda que não basta a quantidade de anos escolares e sim melhorar a capacidade de aprendizagem.

Segundo Sertek, (2007, p. 45) "a flexibilidade da organização, sua capacidade de fornecer respostas mais rápidas e adequação de 
soluções às novas exigências dos clientes requerem formas estruturais mais ágeis $e$ pessoas melhor capacitadas".

Além disso, pessoas capacitadas geram mudanças para a sociedade, pois não há dúvidas que o conhecimento constitui a base de sustentação da sociedade e organização. 0 conhecimento não deve ser visto como um fim último para as empresas, mas como uma ferramenta que se adquire em um novo processo de aprendizagem organizacional, sendo assim:

[..] estas mudanças modificam as demandas de habilidades $e$ conhecimentos que requerem as empresas. Conhecimentos e habilidades se convertem em um elemento-chave para competir na era do conhecimento às empresas devem localizarse onde tenham mais facilidades e acesso a este conhecimento, ao mesmo tempo em que direcionarão suas políticas de recursos humanos para adequada localização destes recursos escassos [...] (SERTEK, 2012, p. 44)

O conhecimento desenvolve um país ou região e, todos os níveis educacionais são importantes. Contudo, o ensino superior em particular tem como objetivo contribuir para o desenvolvimento de pessoas capazes de enfrentar os desafios do século XXI e, os egressos com nível superior melhoram a sociedade e distribuem conhecimentos.

Países com um percentual maior de universitários são mais eficientes na gestão de recursos, atingem níveis de desenvolvimento econômico melhores, suas empresas são mais rentáveis e os trabalhadores têm remunerações melhores, todo esse ciclo virtuoso gera bem-estar social.

Assim, compreender o que acontece com os alunos após frequentar o curso de Administração de empresas (doravante ADM) da UNOESTE vem de encontro com a necessidade global de medir a eficácia e a eficiência do ensino.

Entende-se que esse conhecimento pode ser expresso de duas formas: na efetividade dos conhecimentos teóricos, no atual emprego, dando ao egresso a oportunidade de melhorar de cargo, ou estimulando novos empreendedores, na abertura de empresas mais eficientes e inovadoras. Em ambos os casos o principal efeito segundo a literatura é o aumento da eficiência, gerando mais renda e riqueza em um determinado país ou região.

Os alunos mais qualificados são os agentes de mudança essencial no desenvolvimento econômico, com esse pensamento surgiu o objeto desta pesquisa buscando compreender: Os alunos têm melhores ganhos (financeiros) após o termino do curso de Administração de Empresas da UNOESTE?

A universidade UNOESTE tem como foco principal transformar os alunos, dar uma profissão e capacitá-los para serem profissionais diferenciados. $O$ impacto do ensino superior vai além, modifica o prisma e o conceito dos discentes, tornando o ser humano mais consciente do ponto de vista social, dando condições de desenvolver conhecimentos para o futuro. Como consequência, a região em que a universidade se instalada tem também um impacto positivo de desenvolvimento.

Atualmente o mercado exige um ganho exponencial de conhecimento e desenvolvimento tecnológico. Esse fenômeno tem produzido um novo contexto socioeconômico, as pessoas estão buscando diferentes formas de aprimoramento no Oeste Paulista.

A UNOESTE é uma instituição de comprometimento e caráter formativo, sua missão expressa que ela deve: "produzir, sistematizar e socializar o saber", para realizar sua missão a universidade deve rever de maneira sistemática seu planejamento estratégico. Essa estratégia é um instrumento de fundamental importância na definição dos seus rumos e, com um processo participativo, a comunidade e a universitária podem pensar no futuro.

Assim sendo, este trabalho contribui para a missão da universidade, ou seja, compreender o caminho dos egressos após sua formação, trazendo um bom feedback para rever métodos e processos de ensino e aprendizagem.

\section{FUNDAMENTAÇÃO TEÓRICA}

Podemos encontrar no mundo empresarial dois tipos de empreendedores, os chamados empreendedores por oportunidade e por necessidade, o primeiro analisa o mercado, encontra uma oportunidade, estuda as possibilidades e por fim faz o investimento. 
A escola, o ensino e o conhecimento devem preparar o cidadão e induzi-lo a investir quando for uma oportunidade, pois 0 investimento por necessidade normalmente é feito com pouco preparo, conhecimento e normalmente têm baixos índices de sucesso.

Desta forma, o processo universitário tem como objetivo despertar vocações, criar ambições, formar gestores, isso porque o processo universitário dá uma visão ampliada do mercado. É importante observar que em uma classe, há heterogeneidade, dada pela presença de diferentes histórias precedentes, contextos sociais e culturais. Contudo, na educação é fundamental discutir crescimento, desenvolvimento, inclusão social e conhecimento de cada indivíduo.

De acordo com Freire (1979) a educação é uma resposta para o conhecimento e desenvolvimento, com a educação é possível ter autoconhecimento e, com ele podemos observar que a população se transforma e a concepção da relação entre escola, sociedade e cidadão tornase plena.

A qualidade na educação passa, necessariamente, pela quantidade. Em uma democracia plena, quantidade é sinal de qualidade social e, se não tem a quantidade total atendida, não se pode falar em quantidade. (CORTELLA, 2000, p. 14)

A educação refere-se a todos os processos pelos quais as pessoas adquirem compreensão do mundo, bem como capacidade para lidar com seus problemas. Segundo Vargas e Abbad (2006), as pessoas podem educar-se lendo livros, explorando seu meio ambiente, viajando, conversando e até mesmo assistindo aulas.

Dentro deste contexto adentramos na importância da formação superior, em um mercado cada vez mais competitivo, não há quem duvide da importância de um diploma superior como pré-requisito para conquistar estabilidade em um concurso publico, ou melhores condições na profissão na iniciativa privada, em ambos os casos estes egressos terão melhores salários.

De acordo com dados do IBGE (2013), um profissional com diploma superior ganha duas vezes mais do que aquele que não apresenta curso superior. Assim, pode-se afirmar que todos os dados demonstram que pessoas com o terceiro grau completo têm maiores oportunidades que os demais, aqui no Brasil.

Segundo Psacharopoulos (1994) as estimativas dos retornos brutos com a educação são positivas. Em seu estudo com 98 países, o aumento de anos escolares tem um impacto positivo para o país e principalmente para aqueles que ficaram mais anos na escola. Psacharopoulos e Patrinos (2002), afirmaram que a educação na América Latina e no Brasil tem impactos melhores e maiores que em outros países em desenvolvimento, em relação à renda e igualdade de gênero.

Gráfico 1. Aumento de renda por ciclo escolar completo

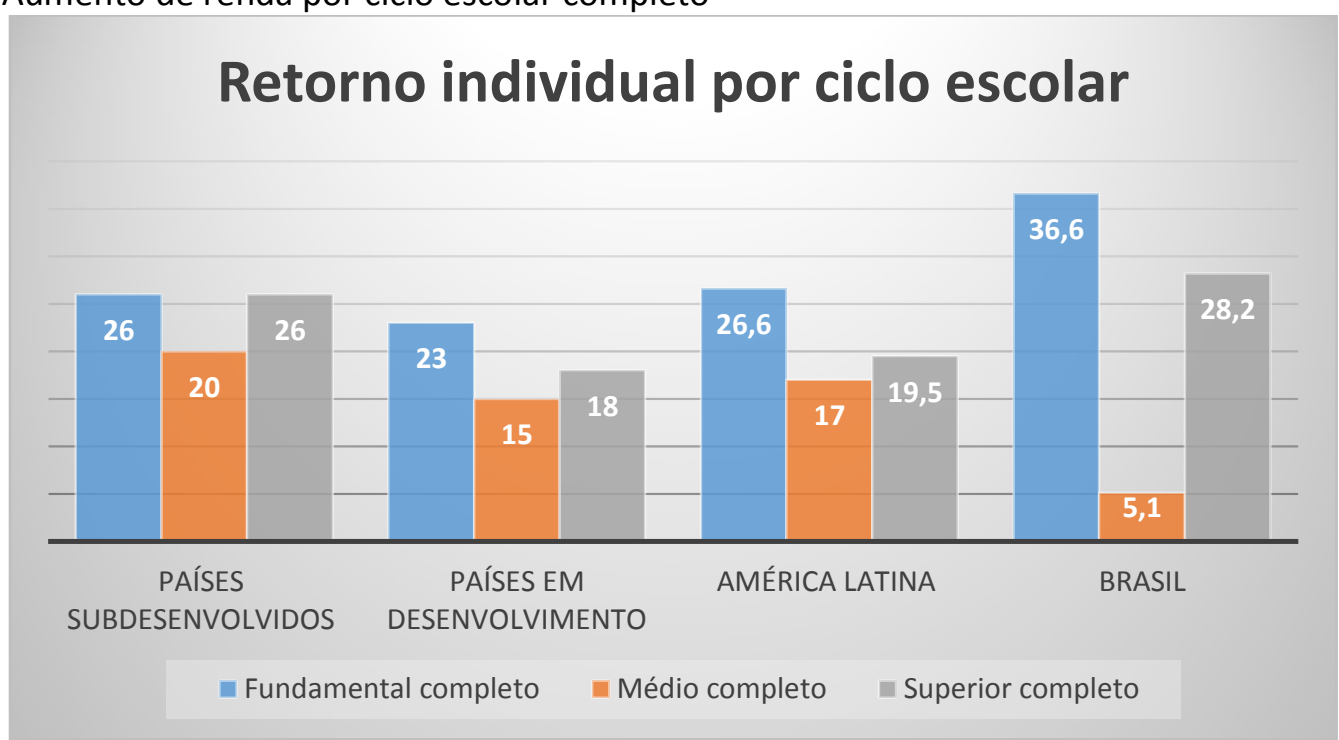

Fonte: Psacharopoulos e Patrinos (2002 p. 13 e 18). Adaptado pelos autores 
Gráfico 2. Educação e igualdade de gênero e renda

\section{Ganho por ciclo escolar e por gênero}

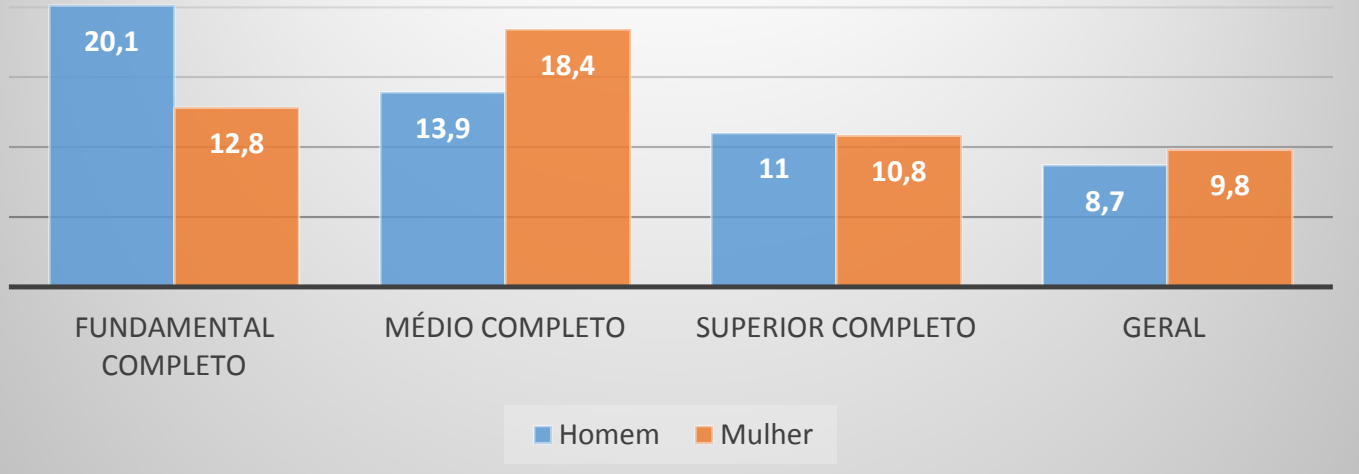

Fonte: Psacharopoulos e Patrinos (2002 p. 15). Adaptado pelos autores

Observamos que a mulher tem procurado se qualificar mais do que o homem no Brasil e na maioria dos países estudados, (IBGE, 2013; PSACHAROPOULOS e PATRINOS, 2002), e com isto, vem diminuindo a diferença entre renda e cargos ocupados na grande maioria dos países.

O curso de administração de empresas é um dos mais procurados no país, abordando uma área do conhecimento fundamentada em normas, funções e princípios elaborados. Estes objetivos determinam a estrutura das organizações, entre os mais importantes podemos citar: a maximização dos lucros e, a gerência de departamentos como financeiro, produção e recursos humanos.

De acordo com Oliveira (2009), a administração por objetivos contribui para o desenvolvimento de instrumentos administrativos específicos, os quais têm sido importantes para a evolução da administração nas organizações.

O profissional de administração tem responsabilidade pelo planejamento, organização, direção e controle de empresas, procurando alocar racionalmente os recursos disponíveis para atingir os objetivos e resultados pré-estabelecidos na gestão empresarial.

Acredita-se que após o término do curso de ADM da UNOESTE, os egressos tenham o conhecimento adequado para empreenderem e/ou para se especializarem e obterem promoções nos seus empregos. Em linhas gerais entende-se que 0 curso superior em administração de empresas da UNOESTE pode modificar positivamente a renda média dos ex- alunos (doravante alumni) quando comparados com os ingressantes.

Desta forma os objetivos específicos se resumem em: mensurar monetariamente os ganhos médios e o desvio padrão da renda dos alunos antes de entrar no curso de ADM. Medir o ganho médio dos alumni no término do curso e um ano depois de concluído. Verificar a empregabilidade dos observados. Identificar o nível de empreendedorismo entre os alumni e verificar se esse empreendedorismo tem impactos sócios econômicos para os envolvidos.

Assim, como objetivo principal este trabalho teve como meta, compreender o desdobramento da vida profissional dos egressos do curso de ADM da UNOESTE, verificando o percentual de empreendedores e gerentes atuais, seus ganhos financeiros e, satisfação pessoal.

\section{MÉTODOS E PROCESSO}

Esse estudo se caracteriza como exploratório e quantitativo, tendo como universo de pesquisa, os egressos do curso de ADM da UNOESTE. Para Gil (2002), a estratégia exploratória tem como objetivo descrever com maior familiaridade o problema, com vista a torná-lo explícito ou a construir hipóteses. Ainda de acordo com o autor, existe a possibilidade de aprimoramento de ideias ou reiteração de hipóteses.

Quanto à abordagem quantitativa, segundo Serapioni (2000), ela aborda diferentes níveis de realidade e "tem como objetivo trazer a luz a dados, indicadores e tendências observáveis" (SERAPIONI, 2000, p. 189). Ainda 
segundo o autor, não há contradição entre a abordagem quantitativa e entrevistas que de algum modo podem ser classificadas como qualitativas, visto que ambas se complementam.

O espaço temporal utilizado é de 7 anos, assim a pesquisa analisará através de levantamento bibliográfica e dados secundários, dos órgãos oficiais como a RAIS e IBGE para fazer um levantamento do perfil médio dos trabalhadores da região de Presidente Prudente.

Para obter dados primários foi enviado um questionário individual, o qual foi compilado online por meio da plataforma Google que permite o preenchimento parcial ou integral do questionário, obtendo gênero, idade, renda, nível de empreendedorismo e, de satisfação com sua renda e condição social.

Estes questionários seguem o padrão da escala desenvolvida por Rensis Likert em 1932 que consiste em fazer uso de uma escala de 1 a 5 no qual 1 representa que o entrevistado discorda fortemente e 5 , que concorda fortemente. Apesar de relativamente antigo, o uso da escala de Likert é um dos processos mais aceitos na literatura mundial (JAMIESON, 2004).

É importante ressaltar que a primeira pergunta era obrigatória, tendo em vista que nela continha a mensagem descritiva e explicativa do TCLE (Termo de Consentimento Livre e Esclarecido) explicando o propósito da pesquisa, a confidencialidade dos dados, o uso dos dados unicamente para fins de pesquisa científica e, assegurando os participantes que em nenhum momento do trabalho serão citados nomes, emails ou quaisquer formas de identificação do participante.

Em outras palavras, o questionário somente poderia ser preenchido e utilizado sob expresso consentimento em formulário específico (TCLE), conforme resolução 466/12 do Conselho Nacional de ética em Pesquisa (CONEP). Assim, ressalta-se que esta pesquisa obteve a aprovação em 09/02/2017 com o CAAE 64.199816.9.0000.5515

Outro aspecto relevante da privacidade dos pesquisados é que no corpo do e-mail enviado existe uma opção de "remover assinatura", de modo que, o pesquisado pode não responder o questionário e também cancelar o e-mail, optando por não receber mais nenhum outro e-mail relacionado com essa pesquisa.

Foram enviados 938 e-mails para os alumni formados entre o primeiro semestre de 2010 até os formados no 20 semestre de 2016, dos quais 39 e-mails voltaram por erros nos bancos de dados. Entre os 899 e-mails considerados válidos, 48 responderam de forma completa representado $5,4 \%$ do total de egressos no período de 7 anos.

De acordo com estudos realizados por Hair et al. (2009) e Johnson (2013) parte desta informação pode ser analisada e compreendida com métodos de estatística simples, por exemplo, uma amostra de $5 \%$ dos sujeitos pesquisados tem uma margem de segurança de $95 \%$ e, portanto, sua representatividade é considerada válida e com grande confiabilidade.

Desse modo, o método de análise fatorial teve como estratégia a pesquisa quantitativa baseada na comparação de dados secundários com os dados primários, do público alvo. Os ganhos ou não dos alunos de ADM da UNOESTE foram comparados com o resto da população da mesma faixa etária e sexo. Os dados foram computados e analisados estatisticamente por meio do software Excel.

Foram analisadas as tendências de remuneração na região de Presidente Prudente, $\mathrm{e}$ dos alumni do curso de ADM, percebeu-se que os ganhos financeiros comparados a dados mundiais, foram superiores. Outro ponto avaliado foi o grau de empreendedorismo dos egressos em comparação ao restante da população.

Por fim considerou-se o grau de satisfação pessoal dos egressos de ADM, estes dados foram analisados com os pontos anteriores dando clara visão que $68,75 \%$ dos egressos estão satisfeitos com o curso.

\section{RESULTADOS}

Nossa amostra por gênero demonstra que o índice feminino está na frente do gênero masculino, comprovando a tendência nacional e os níveis de matrículas do curso. Para evitar discriminações em relação ao gênero, foi adicionado $\mathrm{o}$ item para os egressos homo afetivos. 
Gráfico 3. Perfil dos egressos

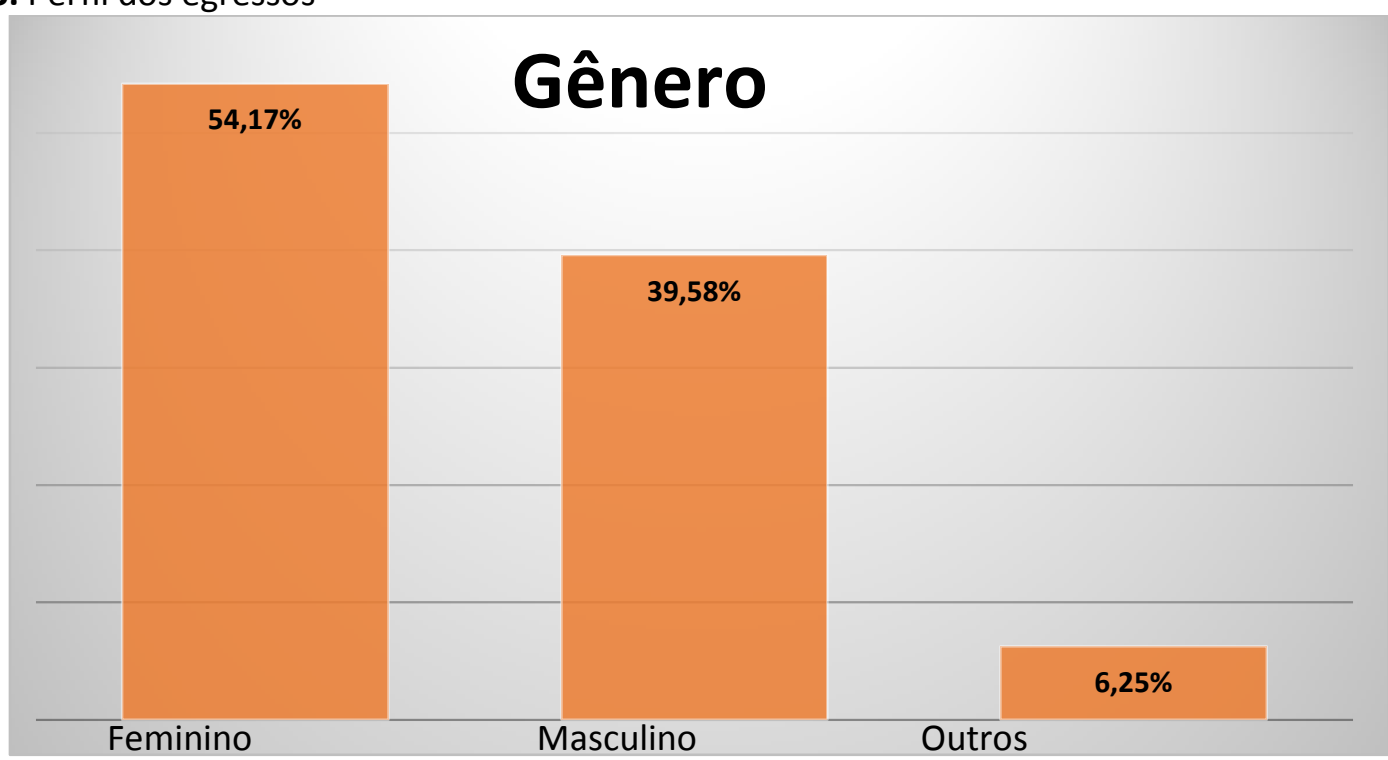

Fonte: Os Autores

Nossa amostra tem idade média de 26,6 anos (gráfico 4), iniciando pelos alunos com idade mínima de 17 anos, os quais estão ingressando cada vez mais nos cursos superiores. Por outro lado, notamos que a quantidade de alunos com mais de 35 anos é relativamente pequena.

Pessoas com idade mais elevada, tem mais dificuldade de ingressar em uma universidade, e sem o curso superior tem também, menos oportunidades no mercado de trabalho. Para romper esse ciclo, estes alunos procuraram ingressar no curso superior, aprimorando seus conhecimentos a fim de fortalecer seu currículo e até mesmo buscando experiência para abrir seu próprio negocio. Talvez esse pensamento explique os mais de $6 \%$ de alunos com idade superior a 40 anos.

Gráfico 4. Perfil dos egressos

\section{Perfil da amostra}

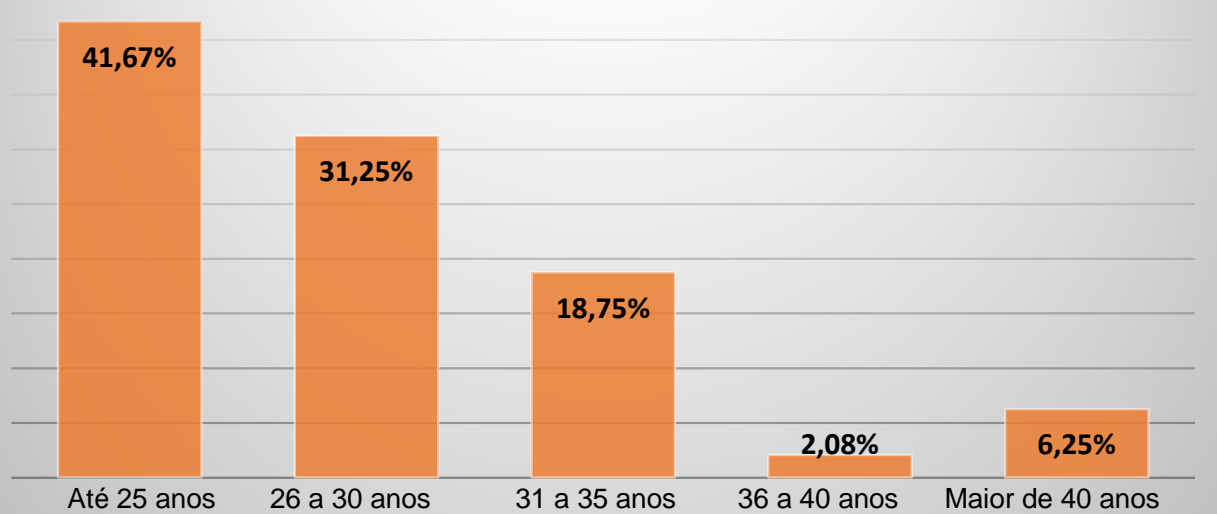

Fonte: Os Autores.

Outro resultado relevante foi a evolução salarial superior à média nacional, demonstrada por Psacharopoulos e Patrinos (2002). Em nossa amostra, o aumento da renda média foi de $66 \%$, entre os alunos quando eram ingressantes comparados com sua renda enquanto alumni.
Os resultados demonstram que a renda é superior à média salarial do Oeste Paulista, tendo em vista que, segundo IBGE o valor médio dos salários da região é de $R \$ 1.111,80$ reais, ou seja, de 1,19 salários mínimos, enquanto que a média ponderada da amostra é de 3,6 salários mínimos. 
Naturalmente pode-se deduzir que esses valores são consequência da falta de qualificação ou média de escolaridade da população, já que segundo o IBGE (2013), a região do Oeste Paulista tem em média 6,3 anos de escolaridade. Além disso, é preciso considerar que pessoas com baixo índice de escolaridade tem poucas oportunidades de trabalho e, com poucas oportunidades os salários continuam com baixos.

Gráfico 5. Evolução salarial

\section{Evolução salarial}

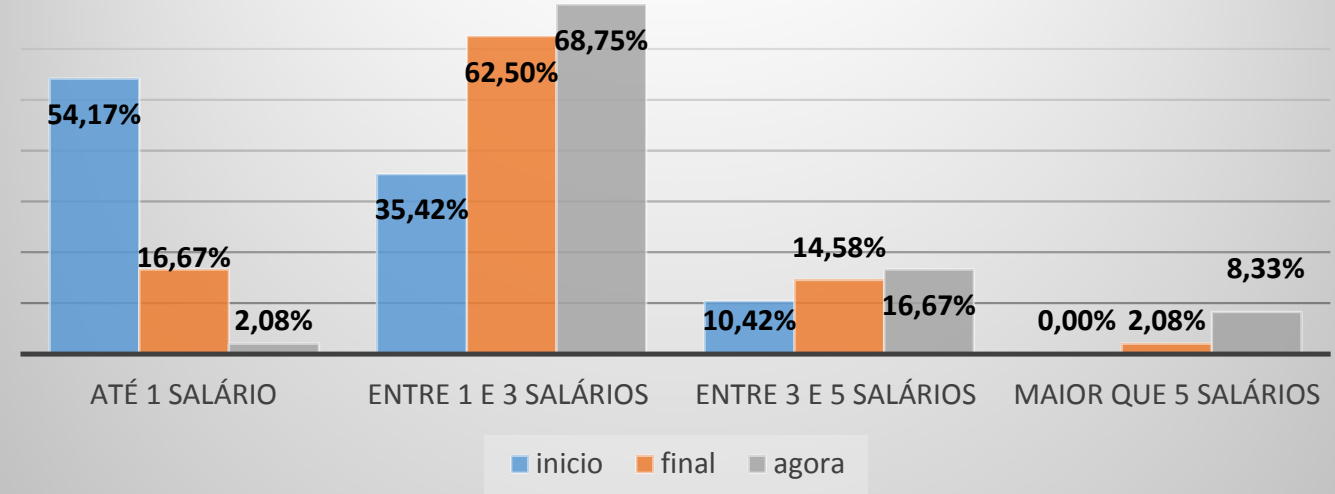

Fonte: Os Autores.

Provavelmente a questão salarial influencia e reflete no grau de satisfação dos egressos considerando-se que encontramos uma satisfação próxima de $90 \%$, e como veremos nos itens seguintes, além de salários melhores que a média da região, os alumni têm também melhores colocações no mercado.

Gráfico 6. Satisfação com o curso de ADM

\section{Curso de ADM}

Fonte: Os Autores.

Outro fato positivo, é o percentual de desempregados entre os egressos, apesar de o desemprego nacional estar em $13,7 \%$ e, o da região do Oeste Paulista estar em 8,1\% (SILVEIRA; CAVALLINI, 2017), apenas $6,25 \%$ dos egressos encontram-se desempregados e mais de $60 \%$ deles, estão em posições gerenciais ou estratégicas das empresas que estão trabalhando, demonstrando que o curso superior foi uma ferramenta importante para a mobilidade social. 
Gráfico 7. Posicionamento dos egressos no mercado.

\section{Posição no mercado}

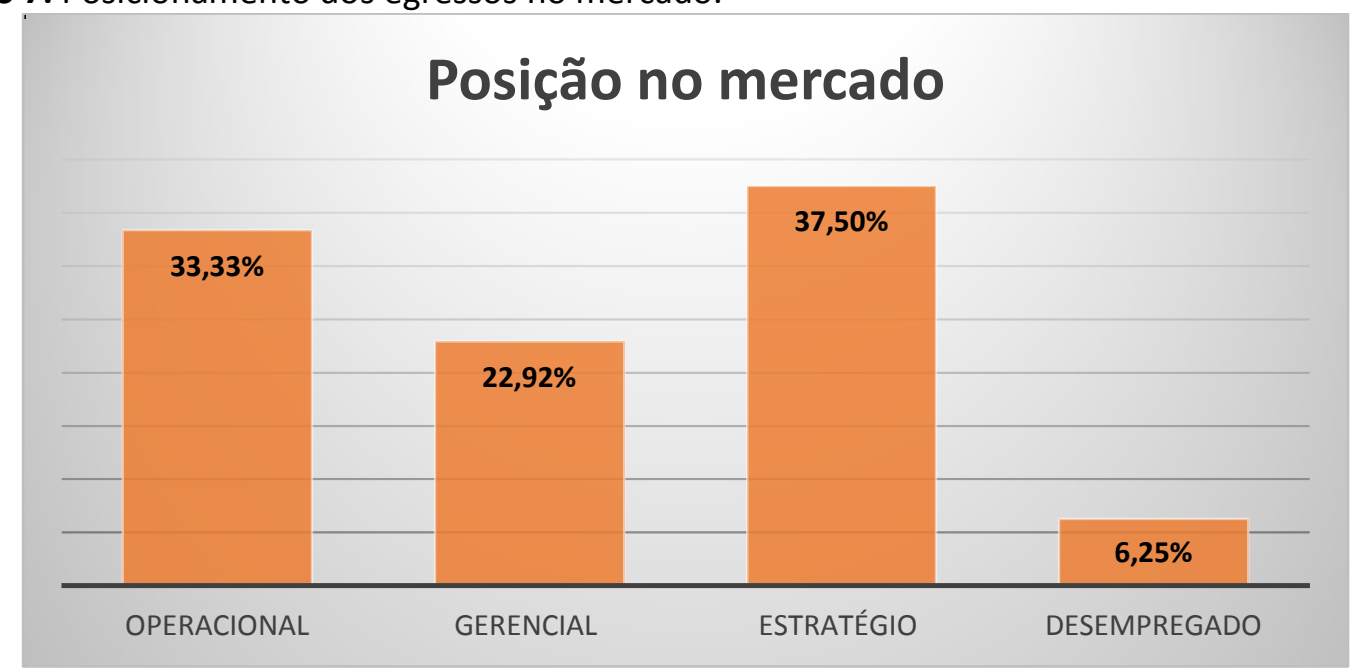

Fonte: Os Autores.

Ao mesmo tempo, foram detectados alguns pontos que devem ser revistos e analisados futuramente, como por exemplo, o fato de que o empreendedorismo não é uma característica entre os alumni. O numero de empreendedores entre os egressos ainda é pequeno, a média nacional de empreendedorismo entre pessoas com terceiro grau completo segundo o IBGE é de $11,3 \%$, e a do curso de ADM de 8,33\% (LEAL, 2012).

Gráfico 8. Perfil dos egressos.

\section{Perfil do egressos}

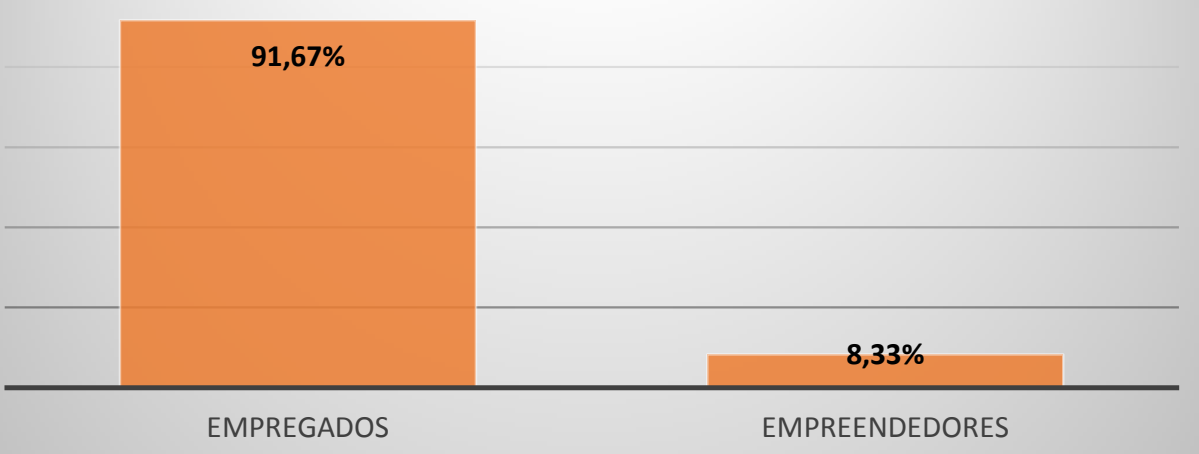

Fonte: Os Autores.

Ao mesmo tempo, observa-se também que, a diferença salarial entre homens e mulheres existe ao entrar na universidade e persiste mesmo após a faculdade. Para as mulheres em média seus salários são menores ao entrar na universidade e na vida pós-formadas, e o nível de desemprego também é maior entre as mulheres.

Este fato é preocupante, pois como já colocado, as mulheres são a maioria dos formandos e buscam a universidade para diminuir ou eliminar o gap entre gêneros existente. 
Gráfico 9. Gap salarial entre gêneros

\section{Gap salarial entre gênero}

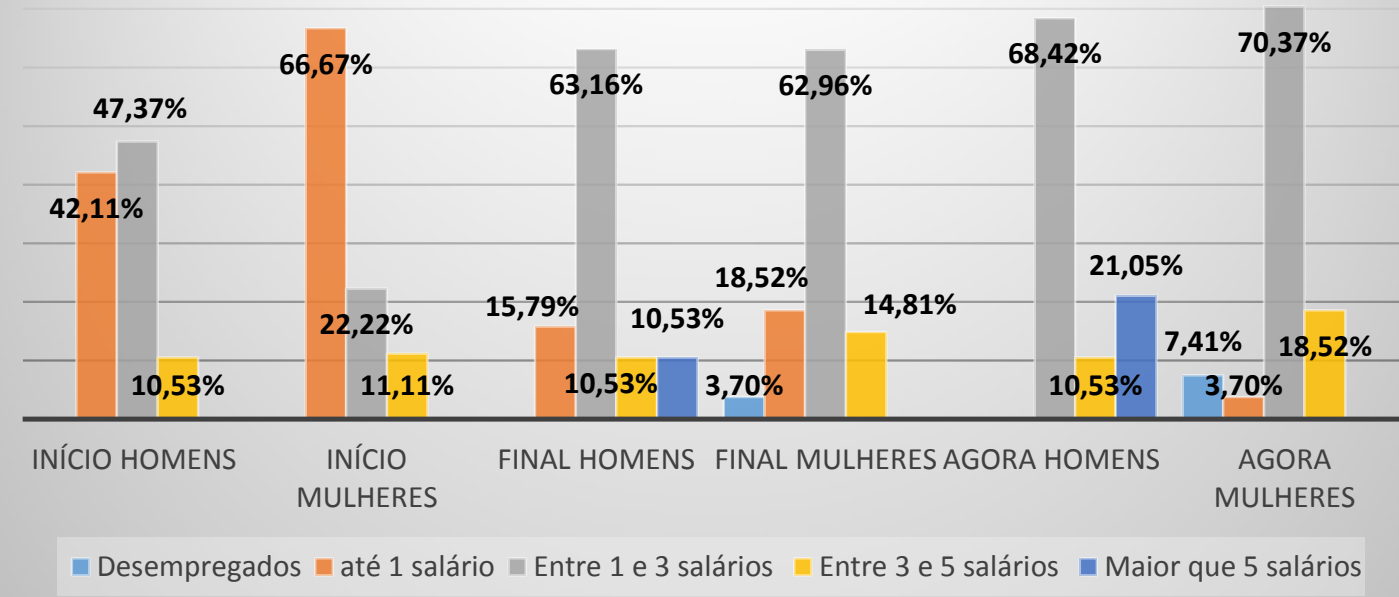

Fonte: Os Autores.

\section{DISCUSSÃO}

A pesquisa demonstrou grande interesse feminino no curso de ADM devido às mudanças nos programas educacionais que abriram espaço para as mulheres.

$O$ curso de ADM demonstra grande aceitação de gêneros, sem preconceito, visto que $6,25 \%$ assumem a posição homoafetiva, pois a universidade e o curso em particular, atuam com o desenvolvimento de programas, pesquisas e projetos especiais com o objetivo de difundir os direitos de cada cidadão e combater a perseguição e/ou bullying com qualquer dos seus alunos.

Futuramente deve-se compreender melhor a questão do empreendedorismo, tanto por necessidade quanto por oportunidade, tendo em vista que ambas podem dar certo ou errado, dependendo da demanda do local onde o egresso irá empreender.

Apesar dos esforços ainda existe um gap dos ganhos de homens e mulheres, refletido na desigualdade de alguns cargos e profissões. Espera-se que essa discrepância possa ser corrigida com o passar dos anos, porém é necessário estudar este fenômeno, e deixar claro os motivos da sua existência, colaborando na indicação de soluções para o fim da desigualdade no mercado de trabalho.

A partir das informações coletadas, considerou-se que os salários de homens e mulheres têm desigualdade, possivelmente por conta da herança cultural machista, ou ainda, da entrada tardia das mulheres no mercado de trabalho, que passaram a buscar condições igualitárias a partir das décadas de 1960 e 1970. Certamente outros fatores poderiam também ser elencados aqui, contudo, esse não é o foco desse estudo.

Além disso, atualmente a desigualdade vem mudando, espera-se que rapidamente, desta forma teremos igualdade entre a colocação profissional e a remuneração de gêneros. Assim, espera-se que as possíveis diferenças fiquem apenas no mérito de cada trabalhador e não no seu gênero.

\section{CONCLUSÃO}

Por meio do estudo feito, foi possível encontrar uma série de informações importantes sobre a relação entre formação acadêmica e mercado de trabalho dos formandos do curso de administração. Entre os resultados, foi possível concluir que os ganhos financeiros dos egressos do curso de ADM foram acima da média nacional de $28,2 \%$ demonstrando uma qualidade do curso e talvez, uma necessidade da região que futuramente deva ser estudada, devido à alta procura pelo curso de ADM na UNOESTE. Como retrato desta realidade, o egresso se torna cada vez mais valorizado, procurando aprimorar ainda mais o seu currículo.

O empreendedorismo acontece com qualidade, visto que àqueles que se declararam empreendedores são os que têm a melhor média salarial e demonstram mais satisfação. Os 
números positivos fazem refletir que possivelmente, com um ambiente agradável, poderíamos criar mais oportunidades de crescimento pessoal e valorização dos profissionais, fazendo com que o retorno se torne mais rápido e mais fácil.

Por fim, foi possível analisar pela primeira vez o perfil dos egressos do curso de ADM, respondendo questionamentos importantes de colegas que estão terminando o curso, dos alunos que estão escolhendo o curso como sua futura profissão e as nossas, já que seremos egressos proximamente.

\section{REFERÊNCIAS}

CORTELLA, M. S. A escola e o conhecimento: fundamentos epistemológicos e políticos.3. ed. São Paulo : Cortez , 2000.

FREIRE, P. Educação e mudanças. Rio de Janeiro: Paz e Terra, 1979.

GIL, A. C. Como elaborar projetos de pesquisa. 4. ed. São Paulo: Atlas, 2002.

JAMIESON, S. Likert Scales: how to (ab)use them. Medical Education, v. 38, 2004. Disponível em: DOI10.1111/J.1365-2929.2004.02012.X Acesso em: 22 abr. 2017.

JOHNSON, V. E. Revised standards for statistical evidence. PNAS, v. 110, n. 48, 2013. Disponível em: DOI 10.1073/PNAS.1313476110. Acesso em: 22 abr. 2017.

LEAL, L. N. Só $11,3 \%$ da população adulta têm faculdade, diz IBGE: quase metade da população adulta brasileira não completou o curso fundamental. 2012. Disponível em: http://exame.abril.com.br/brasil/so-11-3-dapopulacao-adulta-tem-faculdade-diz-ibge/ Acesso em: 30 abr.2017.

IBGE. Instituto Brasileiro de Geografia e Estatística. Curso Superior: 2010. 2013. Disponível em:<http://biblioteca.ibge.gov.br/visualizacao/in strumentos de coleta/doc2601.pdf>. Acesso em: 10 set. 2016.

HAIR, Jr. et al. Análise multivariada de dados. 6. ed. [S.I.]:Bookman, 2009. v.1.
OLIVEIRA, D. P. Teoria geral da administração: edição compacta. São Paulo: Atlas, 2009.

Disponível em:

https://integrada.minhabiblioteca.com.br/\#/book s/9788522464951/cfi/126!/4/2@100:0.00.

Acesso em: 03 set. 2016.

PSACHAROPOULOS, G. Returns to investment in education: a global update. World Development, v. 22, n. 9, p. 1325-43, 1994.

PSACHAROPOULOS, G.; PATRINOS, H. A. Returns to investment in education: a further update. World Bank Policy Research Working Paper, n. 2881, sep., 2002.

VARGAS, M. R.; ABBAD, G. D. Bases conceituais em treinamento, desenvolvimento e educação: TD\&E. In: BORGES-ANDRADE, J. E.; ABBAD, G.; MOURÃO, L. Treinamento, desenvolvimento e educação em organizações e trabalho: fundamentos para a gestão de pessoas. Porto Alegre: Artmed, 2006. p. 137-158.

SERTEK, P. Empreendedorismo. Curitiba: Intersaberes, 2012.

SERTEK, P. Empreendedorismo. Curitiba: Ipbex ,2007.

SERAPIONE, M. Métodos qualitativos e quantitativos na pesquisa social em saúde: algumas estratégias para a integração. Ciência \&Saúde Coletiva, v. 5, n. 1, p. 187-192, 2000.

SILVEIRA, D.; CAVALLINI, M. Desemprego fica em $13,7 \%$ no 10 trimestre de 2017 e atinge 14,2 milhões: essa é a maior taxa da série do indicador, iniciada em 2012. Em 3 anos, número de desempregados mais que dobrou no país. 2017. Disponível em: http://g1.globo.com/economia/noticia/desempre go-fica-em-137-no-1-trimestre-de-2017.ghtml Acesso em: 30 abr. 2017.

TAN, J.P. et al. Workforce development in developing countries: a framework for benchmarking. 2011

Disponível em:

http://siteresources.worldbank.org/EDUCATION/ Resources/278200-1290520949227/75758421336502112143/WfD FrameworkPaper.pdf

Acesso em: 10 abr. 2017 
Recebido para publicação em 25/07/2017

Revisado em 16/08/2017

Aceito em 18/09/2017 